\title{
Cardioversion of Atrial Fibrillation (RHYTHM-AF) International Registry in Poland
}

\author{
Marek Kiliszek ${ }^{1}$, Grzegorz Opolski ${ }^{1}$, Piotr Włodarczyk ${ }^{2}$, \\ Rafał Dąbrowski ${ }^{3}$, Piotr Ponikowski ${ }^{4}$ \\ ${ }^{1} 1^{\text {st }}$ Chair and Department of Cardiology, Medical University of Warsaw, Warsaw, Poland \\ ${ }^{2} \mathrm{MSD}$, Warsaw, Poland \\ ${ }^{3} 2^{\text {nd }}$ Ischemic Heart Disease Department, Institute of Cardiology, Warsaw, Poland \\ ${ }^{4}$ (National Co-ordinator of RHYTHM-AF in Poland) Center for Heart Disease, \\ Clinical Military Hospital, Wroclaw, Poland
}

\begin{abstract}
Background: A key procedure of the rhythm control strategy in atrial fibrillation $(A F)$ is cardioversion to normal sinus rhythm. The aim of the present study was to provide a review of treatment patterns for the cardioversion of patients with AF in a hospital setting in Poland and document the success rate of various cardioversion procedures.

Methods: We herein present the results from Poland of a prospective observational study to characterize patients with recent onset episodes of $A F$ for whom cardioversion is one of the planned therapeutic options - the RHYTHM-AF registry. Consecutive patients in the hospital setting, age $>18$ years, with documented $A F$ at the time of enrollment, excluding those with atrial flutter and those treated with vernakalant, were recruited. No treatment was recommended nor discouraged.

Results: Five hundred and one patients were recruited (mean age $64.2 \pm 12.1$ ), with 294 (58.7\%) patients finally undergoing cardioversion. Primary electrical cardioversion (ECV) was successful in 131 (88.5\%) patients. Primary pharmacological cardioversion (PCV) was successful in 110 (75.3\%) patients. Amiodarone and propafenone were most commonly used (52.1\% and $24.7 \%$, respectively). Fourteen complications and adverse events were recorded (no stroke was observed).

Conclusions: Conversion to sinus rhythm was attempted in $<60 \%$ of the patients with $A F$ admitted to the hospital with an intention to terminate arrhythmia. ECV was successful in $\sim 90 \%$ of the patients, while PCV in 75\% of the patients (amiodarone and propafenone were most commonly used). The rate of complications was low (2.8\%). (Cardiol J 2014; 21, 5: 484-491)
\end{abstract}

Key words: atrial fibrillation, electrical cardioversion, pharmacological cardioversion, registry

Address for correspondence: Marek Kiliszek, MD, $\mathrm{PhD}, 1^{\text {st }}$ Chair and Department of Cardiology, Medical University of Warsaw, ul. Banacha 1a, 02-097 Warszawa, Poland, tel: +48 2259929 58, fax: +48 22599 19 57, e-mail: kiliszek@mp.pl Received: 24.09.2013

Accepted: 21.01.2014 


\section{Introduction}

Atrial fibrillation (AF) is the most common arrhythmia observed in clinical practice, with prevalence increasing with age. It has been estimated that over 6 million people in the European Union have AF and the number has doubled during the last 50 years due to aging of the population [1]. $\mathrm{AF}$ increases mortality and the risk of stroke and decreases quality of life [2].

Two strategies of $\mathrm{AF}$ treatment can be applied: rhythm control or rate control [1]. A key procedure in the rhythm control strategy is cardioversion to sinus rhythm (SR), which can be achieved through pharmacologic or electrical means. Electrical cardioversion (ECV) is proven more effective than pharmacological cardioversion (PCV) [3], but it is costly, requires presence of an anesthesiologist and can be time-consuming.

The aim of the present manuscript is to provide a review of treatment patterns for the cardioversion of patients with recent-onset $\mathrm{AF}$ in hospital setting in Poland and document the success rate of various cardioversion procedures.

\section{Methods}

\section{Study design}

RHYTHM-AF was a prospective observational study conducted in 10 countries: Australia, Brazil, France, Germany, Italy, the Netherlands, Poland, Spain, Sweden, and the United Kingdom. Patients with recent-onset of $\mathrm{AF}$ considered for cardioversion were enrolled from participating hospitals and acute care centers between May 2010 and June 2011 [4]. In this manuscript, only results from Poland will be presented.

\section{Study population}

Centers recruiting patients were selected as representatives of this way of treating $\mathrm{AF}$ in the participating countries. All patients considered for the study were at least 18 years old with documented AF, confirmed by electrocardiogram and cardioversion was one of the planned therapeutic options. All patients signed an informed consent. Only patients who were already enrolled in the current trial, otherwise enrolled in a separate trial, and patients with atrial flutter were excluded.

PCV was considered successful if SR or atrial rhythm was obtained within $24 \mathrm{~h}$ following the initiation. Time to SR was, however, noted separately. ECV was defined as successful if SR was obtained and maintained for at least $10 \mathrm{~min}$ following the last shock.
All patient data were collected via a remote web based data collection form using the multilingual software solution $\mathrm{EBogen}^{\odot}$, developed by the IHF Ludwigshafen, Germany (the coordinating center for the study).

\section{Statistical analyses}

All data are presented as mean \pm standard deviation, median and interquartile (IQR) range or number and percent of population, depending on characteristic of the parameter. All comparisons were made using $\chi^{2}$ or Kruskal-Wallis tests.

\section{Results}

In Poland, 501 patients in 15 centers were included into the analyses. Major characteristics of the study group are shown in Table 1 . Two hundred and ninety four patients underwent cardioversion (148 - primary ECV, 146 - primary PCV), while in 207 patients no cardioversion was attempted. In almost half of these patients ( $\mathrm{n}=92,44.4 \%)$, cardioversion was planned following the discharge, in $26.6 \%$ (55 patients) there was spontaneous conversion to SR. Flow of the patients and detailed reasons for not attempting to cardioversion are shown in Figure 1.

\section{Comparison between primary ECV and primary PCV patients}

Clinical characteristic of patients who primarily underwent ECV included younger aged and less frequently women than those cardioverted pharmacologically. The distribution of concomitant diseases (hypertension, diabetes, coronary artery disease) was comparable between the ECV and $\mathrm{PCV}$ groups (and so was $\mathrm{CHADS}_{2}$ and $\mathrm{CHA}_{2} \mathrm{DS}_{2}-$ -VASc score) with the exception of heart failure and valvular heart disease - these patients more frequently underwent ECV. Major differences between ECV and PCV patients were AF characteristics: among patients who underwent ECV, paroxysmal $\mathrm{AF}$ was less frequent, persistent $\mathrm{AF}$ was more common, and the duration of the longest previous episode was different (91.3 vs. 0.8 days), as was the duration of the current episode (57.0 vs. 0.0 days).

\section{Electrical cardioversion}

One hundred and forty eight patients underwent primary ECV (50.3\% of patients who underwent any cardioversion). The primary reason for admission among the vast majority of patients was $\mathrm{AF}(92.6 \%)$. Median time to cardioversion among 
Table 1. Major characteristic of the registry group (percentages and numbers or medians and quartiles or mean and standard deviation are given).

\begin{tabular}{|c|c|c|c|c|}
\hline $\begin{array}{l}\text { Demographics } \\
\text { and risk factors }\end{array}$ & $\begin{array}{c}\text { Total } \\
\text { (n=501) }\end{array}$ & $\begin{array}{l}\text { Primary ECV group } \\
(\mathbf{n}=148)\end{array}$ & $\begin{array}{l}\text { Primary PCV group } \\
(\mathrm{n}=146)\end{array}$ & $\mathbf{P}^{*}$ \\
\hline Age & $64.2 \pm 12.1$ & $61.6 \pm 11.7$ & $66.8 \pm 12.7$ & 0.0003 \\
\hline Women & $193(38.7 \%)$ & $40(26.8 \%)$ & $72(49.3 \%)$ & 0.0001 \\
\hline Body mass index & $29.1 \pm 4.6$ & $29.3 \pm 4.7$ & $28.6 \pm 4.5$ & 0.19 \\
\hline Hypertension & $375(75.0 \%)$ & $108(73 \%)$ & $121(82.9 \%)$ & 0.056 \\
\hline Diabetes & $104(20.8 \%)$ & $31(20.8)$ & $30(20.5 \%)$ & 0.95 \\
\hline Hyperlipidemia & $238(52.3 \%)$ & $79(55.6 \%)$ & $75(60.5 \%)$ & 0.82 \\
\hline CAD & $124(24.8 \%)$ & $36(24.2 \%)$ & $36(24.7 \%)$ & 0.95 \\
\hline Previous MI & $80(16.0 \%)$ & $25(16.8 \%)$ & $21(14.4 \%)$ & 0.66 \\
\hline Heart failure & $120(24.0 \%)$ & $49(32.9 \%)$ & $21(14.4 \%)$ & 0.0003 \\
\hline Valvular heart disease & $90(18.5 \%)$ & $36(24.2 \%)$ & $13(9.6 \%)$ & 0.0007 \\
\hline $\mathrm{CHADS}_{2}$ score & $1.5 \pm 1.0$ & $1.5 \pm 0.9$ & $1.6 \pm 1.0$ & 0.37 \\
\hline $\mathrm{CHA}_{2} \mathrm{DS}_{2}$-VASc score & $2.7 \pm 1.7$ & $2.5 \pm 1.6$ & $2.9 \pm 1.6$ & 0.038 \\
\hline \multicolumn{5}{|l|}{ AF characteristic } \\
\hline First detected episode of AF & $88(17.6 \%)$ & $11(7.4 \%)$ & $44(30.1 \%)$ & $<0.0001$ \\
\hline Paroxysmal AF & $191(38.1 \%)$ & $27(18.1 \%)$ & $89(61.0 \%)$ & $<0.0001$ \\
\hline Persistent AF & $204(40.7 \%)$ & $105(70.5 \%)$ & $11(7.5 \%)$ & $<0.0001$ \\
\hline Chronic AF & $11(2.2 \%)$ & $3(2.0 \%)$ & $1(0.7 \%)$ & 0.62 \\
\hline $\begin{array}{l}\text { Number of previous } \\
\text { symptomatic episodes }\end{array}$ & $2(1-10)$ & $2(1-6)$ & $5(1-15)$ & 0.01 \\
\hline $\begin{array}{l}\text { Duration of longest } \\
\text { previous episode** }\end{array}$ & $4(0.8-91.3)$ & $91.3(42-274)$ & $0.8(0.2-2.0)$ & $<0.0001$ \\
\hline $\begin{array}{l}\text { Duration of current } \\
\text { episode of } \mathrm{AF}^{* *}\end{array}$ & $1.0(0.0-58.0)$ & $57.0(2.0-167.5)$ & $0.0(0.0-1.0)$ & $<0.0001$ \\
\hline $\begin{array}{l}\text { Time since first episode } \\
\text { of AF ever** }\end{array}$ & $\begin{array}{c}1201.5 \\
(269.0-3551.0)\end{array}$ & $\begin{array}{c}889.5 \\
(239.0-3241.0)\end{array}$ & $\begin{array}{c}1302.0 \\
(263.0-3677.5)\end{array}$ & 0.30 \\
\hline
\end{tabular}

*For the differences between primary ECV and primary PCV groups; ${ }^{*}$ days; AF — atrial fibrillation; CAD — coronary artery disease; $\mathrm{ECV}$ - electrical cardioversion; MI - myocardial infarction; PCV — pharmacological cardioversion

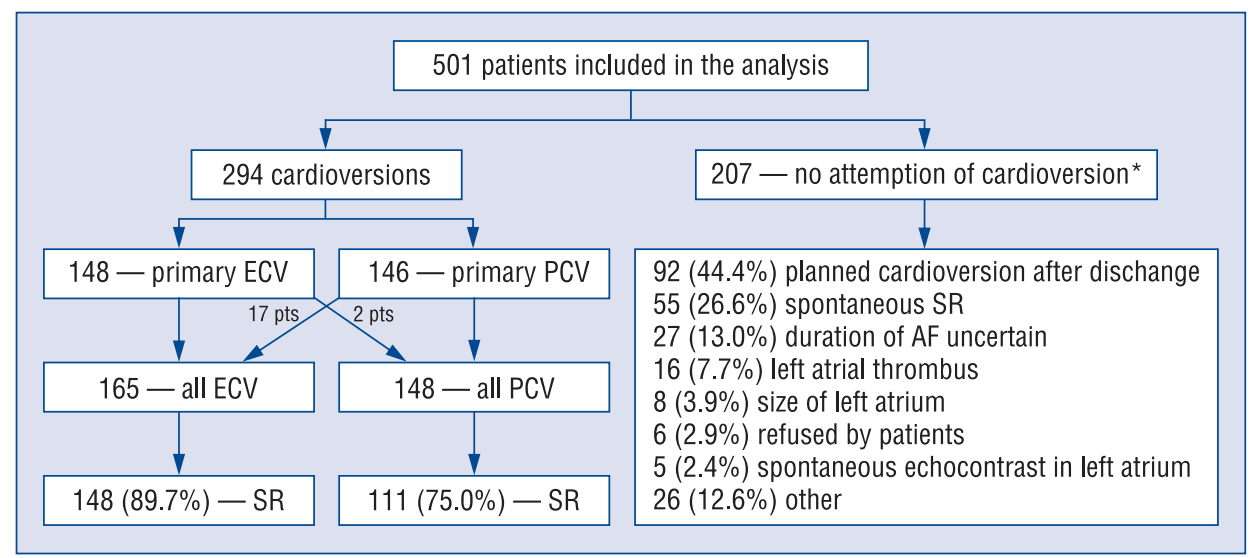

Figure 1. Patient flow in the Polish subset of RHYTHM-AF registry; ${ }^{*}$ Choosing more than one option was available; $\mathrm{AF}$ - atrial fibrillation; ECV — electrical cardioversion; PCV — pharmacological cardioversion; SR — sinus rhythm.

those who underwent primary ECV was $24: 29 \mathrm{~h}$ (IQR 6:21-42:13). A median of total length of hospital stay was 54:19 h (IQR 47:36-92:14) (no significant differences between groups with suc- cessful or unsuccessful ECV). Cardioversion was successful among those who underwent primary ECV in 131 (88.5\%) patients. For 1 patient, treatment was changed from ECV to PCV. 
Table 2. Factors correlated with successful primary electrical cardioversion (ECV) and primary pharmacological cardioversion (PCV).

\begin{tabular}{|c|c|c|c|c|c|c|}
\hline $\begin{array}{l}\text { Demographics } \\
\text { and risk factors }\end{array}$ & $\begin{array}{l}\text { Primary ECV } \\
\text { successful } \\
\text { (n=131) }\end{array}$ & $\begin{array}{l}\text { Primary ECV } \\
\text { not successful } \\
(n=17)\end{array}$ & $\mathbf{P}$ & $\begin{array}{l}\text { Primary PCV } \\
\text { successful } \\
(n=110)\end{array}$ & $\begin{array}{l}\text { Primary PCV } \\
\text { not successful } \\
(n=36)\end{array}$ & $\mathbf{P}$ \\
\hline Age & $61.6 \pm 11.8$ & $61.6 \pm 11.6$ & 0.96 & $66.7 \pm 13.1$ & $67.1 \pm 11.7$ & 0.98 \\
\hline Women & $33(25.0 \%)$ & $7(41.2 \%)$ & 0.16 & $58(52.7 \%)$ & $14(38.9 \%)$ & 0.15 \\
\hline Body mass index & $29.1 \pm 4.8$ & $30.8 \pm 3.6$ & 0.07 & $28.9 \pm 4.5$ & $27.8 \pm 4.1$ & 0.19 \\
\hline Hypertension & $95(72.5 \%)$ & $13(76.5 \%)$ & 0.73 & $93(84.5 \%)$ & $28(77.8 \%)$ & 0.35 \\
\hline Diabetes & $25(18.9 \%)$ & $6(35.3)$ & 0.12 & $26(23.6 \%)$ & $4(11.1)$ & 0.11 \\
\hline Hyperlipidemia & $70(55.1 \%)$ & $9(60.0 \%)$ & 0.72 & $57(61.3 \%)$ & $18(58.1 \%)$ & 0.75 \\
\hline CAD & $30(22.7 \%)$ & $6(35.3 \%)$ & 0.25 & $27(24.5 \%)$ & $9(25.0 \%)$ & 0.96 \\
\hline Previous MI & $22(16.7 \%)$ & $3(17.6 \%)$ & 0.92 & $16(14.5 \%)$ & $5(13.9 \%)$ & 0.92 \\
\hline Heart failure & $43(32.6 \%)$ & $6(35.3 \%)$ & 0.82 & $13(11.8 \%)$ & $8(22.2 \%)$ & 0.12 \\
\hline Valvular heart disease & $29(22.0 \%)$ & $7(41.2 \%)$ & 0.08 & $10(9.3 \%)$ & $3(10.3 \%)$ & 0.87 \\
\hline $\mathrm{CHADS}_{2}$ score & $1.4 \pm 0.9$ & $1.6 \pm 1.0$ & 0.34 & $1.6 \pm 1.1$ & $1.5 \pm 0.8$ & 0.59 \\
\hline $\mathrm{CHA}_{2} \mathrm{DS}_{2}$-VASc score & $2.4 \pm 1.5$ & $2.8 \pm 1.7$ & 0.52 & $3.0 \pm 1.7$ & $2.7 \pm 1.5$ & 0.33 \\
\hline \multicolumn{7}{|l|}{ AF characteristic } \\
\hline $\begin{array}{l}\text { First detected } \\
\text { episode of } A F\end{array}$ & $11(8.3 \%)$ & $0(0.0 \%)$ & 0.22 & $39(35.5 \%)$ & $5(13.9 \%)$ & $<0.05$ \\
\hline Paroxysmal AF & $24(18.2 \%)$ & $3(17.6 \%)$ & 0.98 & $64(58.2 \%)$ & $25(69.4 \%)$ & 0.23 \\
\hline Persistent AF & $91(68.9 \%)$ & $14(82.4 \%)$ & 0.25 & $6(5.5 \%)$ & $5(13.9 \%)$ & 0.10 \\
\hline Chronic AF & $3(2.3 \%)$ & $0(0.0 \%)$ & 0.53 & $0(0.0 \%)$ & $1(2.8 \%)$ & 0.08 \\
\hline $\begin{array}{l}\text { Number of previous } \\
\text { symptomatic episodes }\end{array}$ & $1(1-5)$ & $3(2-10)$ & $<0.05$ & $6(1-15)$ & $2(1-6)$ & 0.07 \\
\hline $\begin{array}{l}\text { Duration of longest } \\
\text { previous episode* }\end{array}$ & $\begin{array}{c}91.3 \\
(30.4-304.4)\end{array}$ & $\begin{array}{c}76.1 \\
(60.9-243.5)\end{array}$ & 0.92 & $\begin{array}{c}0.8 \\
(0.2-2.0)\end{array}$ & $\begin{array}{c}1.0 \\
(0.3-2.0)\end{array}$ & 0.29 \\
\hline $\begin{array}{l}\text { Duration of current } \\
\text { episode of } A F^{*}\end{array}$ & $\begin{array}{c}51.0 \\
(2.0-159.0)\end{array}$ & $\begin{array}{c}127.0 \\
(13.0-271.0)\end{array}$ & 0.32 & $\begin{array}{c}0.0 \\
(0.0-1.0)\end{array}$ & $\begin{array}{c}0.0 \\
(0.0-2.0)\end{array}$ & 0.11 \\
\hline $\begin{array}{l}\text { Time since first } \\
\text { episode of AF ever* }\end{array}$ & $\begin{array}{c}773.5 \\
(222.5-3241.0)\end{array}$ & $\begin{array}{c}1197.0 \\
(413.0-3661.0)\end{array}$ & 0.42 & $\begin{array}{c}1399.0 \\
(299.5-3387.5)\end{array}$ & $\begin{array}{c}950.5 \\
(121.0-4352.5)\end{array}$ & 0.97 \\
\hline \multicolumn{7}{|l|}{$\begin{array}{l}\text { Echocardiographic } \\
\text { parameters }\end{array}$} \\
\hline $\begin{array}{l}\text { Size of left } \\
\text { atrium [mm] }\end{array}$ & $44.0(41.0-47.0)$ & $45.5(43.0-47.5)$ & 0.31 & $41.5(37.0-45.0)$ & $44.0(40.0-46.0)$ & 0.16 \\
\hline $\begin{array}{l}\text { Left ventricular diastolic } \\
\text { dimension }[\mathrm{mm}]\end{array}$ & $52.0(48.0-56.0)$ & $51.0(47.0-58.0)$ & 0.74 & $50.0(45.0-53.0)$ & $50.5(47.0-54.0)$ & 0.50 \\
\hline $\begin{array}{l}\text { Left ventricular ejection } \\
\text { fraction }<45 \%\end{array}$ & $26(27.1 \%)$ & $4(33.3 \%)$ & 0.65 & $6(7.7 \%)$ & $4(18.2 \%)$ & 0.15 \\
\hline
\end{tabular}

Abbreviations - see Table 1

The total number of patients who underwent external ECV (including those converted from PCV) was 165 (98.2\%). Mean energy of the first shock was $157.7 \pm 47.2$, with no differences between successful and unsuccessful cardioversion. One ECV was done transesophageally (but was unsuccessful), and two were made from implantable cardioverter-defibrillator (both successful). An anesthesiologist was present in 135 (81.8\%) cases of all ECVs. SR was eventually obtained in 148 patients among those receiving ECV.

Comparing patients with successful and unsuccessful primary ECV, the only parameter lower in patients with successful primary ECV was the number of previous symptomatic episodes (Table 2). All patients except for one were discharged from hospital. One hundred and fourteen $(86.4 \%) \mathrm{pa}-$ tients with a successful first ECV and 3 (17.6\%, $\mathrm{p}<0.0001$ ) with an unsuccessful ECV were in SR at discharge.

\section{Pharmacological cardioversion}

One hundred and forty six (49.7\%) patients primarily underwent $\mathrm{PCV}$. The primary reason for admission was AF in 121 (82.9\%) patients. Other reasons for admission included acute coronary 
Table 3. Clinical characteristics of the patients who underwent primary pharmacological cardioversion (PCV) depending on the drug.

\begin{tabular}{|c|c|c|c|c|c|}
\hline $\begin{array}{l}\text { Demographics } \\
\text { and risk factors }\end{array}$ & $\begin{array}{c}\text { Amiodarone } \\
\text { or amiodarone } \\
\text { and } B B(n=76)\end{array}$ & $\begin{array}{l}\text { Propafenone } \\
\text { or propafenone } \\
\text { and } B B(n=36)\end{array}$ & $\begin{array}{l}\text { BB as the } \\
\text { only therapy } \\
(n=17)\end{array}$ & $\begin{array}{l}\text { Other } \\
(n=5)\end{array}$ & $\mathbf{P}$ \\
\hline Age & $67.2 \pm 12.7$ & $67.3 \pm 10.6$ & $72.9 \pm 11.0$ & $61.4 \pm 5.7$ & 0.11 \\
\hline Women & $42(55.2 \%)$ & $13(36.1 \%)$ & $11(64.7 \%)$ & $2(40.0 \%)$ & 0.15 \\
\hline Body mass index & $28.1 \pm 4.8$ & $28.9 \pm 3.6$ & $29.2 \pm 4.7$ & $31.1 \pm 2.9$ & 0.23 \\
\hline Hypertension & $63(82.9 \%)$ & $32(88.9 \%)$ & $15(88.2 \%)$ & $4(80.0 \%)$ & 0.82 \\
\hline Diabetes & $15(19.7)$ & $12(33.3 \%)$ & $1(5.9 \%)$ & $1(20 \%)$ & 0.13 \\
\hline Hyperlipidemia & $47(65.3 \%)$ & $19(73.1 \%)$ & $4(40 \%)$ & $4(80 \%)$ & 0.26 \\
\hline Coronary artery disease & $22(28.9 \%)$ & $11(30.6 \%)$ & $2(11.8 \%)$ & $1(20 \%)$ & 0.47 \\
\hline Previous MI & $11(14.5 \%)$ & $9(25.0 \%)$ & $0(0 \%)$ & $1(20 \%)$ & 0.13 \\
\hline Heart failure & $12(15.8 \%)$ & $9(25.0 \%)$ & $0(0 \%)$ & $0(0 \%)$ & 0.09 \\
\hline Valvular heart disease & $8(11.0 \%)$ & $3(10.0 \%)$ & $1(6.3 \%)$ & $0(0 \%)$ & 0.83 \\
\hline $\mathrm{CHADS}_{2}$ score & $1.6 \pm 1.1$ & $1.7 \pm 1.0$ & $1.6 \pm 0.9$ & $1.0 \pm 0.7$ & 0.45 \\
\hline $\mathrm{CHA}_{2} \mathrm{DS}_{2}$-VASc score & $3.0 \pm 1.6$ & $3.2 \pm 1.6$ & $3.1 \pm 1.1$ & $1.8 \pm 1.6$ & 0.43 \\
\hline
\end{tabular}

BB - beta-blockers; MI - myocardial infarction

syndrome in $6(4.1 \%)$ patients, stable coronary disease in $5(3.4 \%)$ patients, heart failure in $4(2.7 \%)$ patients, and valvular heart disease in $3(2.1 \%)$ patients. The median time to initiation of cardioversion among those undergoing primary PCV was 2:14 h (IQR 0:30-17:50). Among these patients, the median time to reach SR was $180 \mathrm{~min}$ (IQR 72-740). A median of total length of hospital stay among patients with primary PCV was $70: 38 \mathrm{~h}$ (IQR 17:50-99:03).

Clinical characteristics among the amiodarone, propafenone, beta-blockers (BB) and "other" groups were not statistically different (Table 3 ). $\mathrm{AF}$ as the primary reason for admission was the least frequent among patients in the amiodarone group; other AF characteristics were not significantly different between the groups (Table 4). The dosage of the drugs and the route of administration are shown in Table 5 . The most popular BB was metoprolol $(88.2 \%$ of the patients treated only with $\mathrm{BB}$ and $87.8 \%$ of all the patients treated with BB). Nine (11.5\%) patients treated initially with amiodarone were also treated with propafenone (all intravenously, a median dose of $140 \mathrm{mg}$ ). Primary PCV was successful in $110(75.3 \%)$ patients. In 17 (10.9\%) patients, ECV was performed following unsuccessful PCV and all were successful (number of shocks $1.1 \pm 0.3$, first shock $129.1 \pm 55.6 \mathrm{~J}$ ). In $2(1.4 \%)$ patients, conversion from AF into atrial flutter or atrial tachycardia was observed. Differences in successful conversion between groups were not statistically significant: from $69.4 \%$ in the propafenone group, to $80.0 \%$ in the other drug group $(\mathrm{p}=0.90)$. The time to reach SR was the longest in the amiodarone group and the shortest in the BB group $(\mathrm{p}<0.01)$, with the same trend in duration of hospital stay $(\mathrm{p}<0.0001)$ (Table 6$)$.

None of the echocardiographic or clinical parameters was different in patients with successful primary PCV in comparison with unsuccessful primary PCV. The only significant difference was in the number of the first detected episode (Table 2). All patients except for two were discharged from hospital. One hundred and six patients (96.3\%) with the initial PCV successful and 19 (52.8\%) patients $(\mathrm{p}<0.0001)$ with the first PCV unsuccessful were in sinus/atrial paced rhythm upon discharge.

\section{Complications and adverse events}

During the hospital stay, 14 (2.8\%) complications and adverse events were recorded. Among them, there was 1 transient ischemic attack, 1 pulmonary embolism, 2 exacerbations of heart failure, 1 ventricular fibrillation, 1 syncope and 5 episodes of sinus syndrome insufficiency.

No stroke, major bleeding, torsade de pointes or hypotension were observed during the hospitalization.

\section{Discussion}

In the present manuscript, we document characteristics and current treatment patterns of patients who were admitted to the hospital to un- 
Table 4. Atrial fibrillation (AF) characteristics of the patients who underwent primary pharmacological cardioversion (PCV) depending on the drug.

\begin{tabular}{|c|c|c|c|c|c|}
\hline AF characteristics & $\begin{array}{c}\text { Amiodarone } \\
\text { or amiodarone } \\
\text { and BB }(n=76)\end{array}$ & $\begin{array}{l}\text { Propafenone } \\
\text { or propafenone } \\
\text { and BB }(n=36)\end{array}$ & $\begin{array}{c}\text { BB as the } \\
\text { only therapy } \\
\text { ( } n=17)\end{array}$ & $\begin{array}{l}\text { Other } \\
(n=5)\end{array}$ & $\mathbf{P}$ \\
\hline $\begin{array}{l}\text { Primary reason for } \\
\text { admission: } A F\end{array}$ & $56(73.7 \%)$ & $33(91.7 \%)$ & $16(94.1 \%)$ & $5(100 \%)$ & $<0.05$ \\
\hline $\begin{array}{l}\text { First detected episode } \\
\text { of AF }\end{array}$ & $29(38.2 \%)$ & $7(19.4 \%)$ & $7(41.2 \%)$ & $0(0.0 \%)$ & 0.07 \\
\hline Paroxysmal AF & $43(56.6 \%)$ & $27(75.0 \%)$ & $9(52.9 \%)$ & $5(100 \%)$ & 0.07 \\
\hline Persistent AF & $3(3.9 \%)$ & $1(2.8 \%)$ & $1(5.9 \%)$ & $0(0.0 \%)$ & 0.92 \\
\hline Chronic AF & $1(1.3 \%)$ & $0(0.0 \%)$ & $0(0.0 \%)$ & $0(0.0 \%)$ & 0.43 \\
\hline $\begin{array}{l}\text { Number of previous } \\
\text { symptomatic episodes }\end{array}$ & $2.0(1.0-10.0)$ & $5.0(2.0-15.0)$ & $10.0(1.0-20.0)$ & $10(5.0-60.0)$ & 0.31 \\
\hline $\begin{array}{l}\text { Duration of longest } \\
\text { previous episode [days] }\end{array}$ & $0.8(0.2-2.0)$ & $0.3(0.1-0.8)$ & $1.0(0.3-1.0)$ & $2.0(2.0-2.0)$ & 0.17 \\
\hline $\begin{array}{l}\text { Duration of current } \\
\text { episode of AF [days] }\end{array}$ & $0.0(0.0-1.0)$ & $0.0(0.0-1.0)$ & $0.0(0.0-1.0)$ & $0.0(0.0-0.0)$ & 0.90 \\
\hline $\begin{array}{l}\text { Time since first episode } \\
\text { of AF ever [days] }\end{array}$ & $\begin{array}{c}589.5 \\
(104.0-2134.0)\end{array}$ & $\begin{array}{c}1901.0 \\
(866.0-4021.0)\end{array}$ & $\begin{array}{c}674.0 \\
(64.0-1609.0)\end{array}$ & $\begin{array}{c}1805.0 \\
(1422.0- \\
-2188.0)\end{array}$ & 0.17 \\
\hline
\end{tabular}

BB - beta-blockers

Table 5. Registry drugs dosage and route of administration.

\begin{tabular}{lccc}
\hline Drug & $\begin{array}{c}\text { Dose [mg] } \\
\text { Median (IQR) }\end{array}$ & \multicolumn{2}{c}{ Route of administration } \\
\cline { 3 - 4 } & $600(300-900)$ & $1(1.3 \%)$ & Oral \\
\hline Amiodarone* $^{*}$ & $300(140-300)$ & $28(71.8 \%)$ & $11(28.2 \%)$ \\
Propafenone* $_{\text {Beta-blockers** }}$ & Not applicable & $8(47.1 \%)$ & $8(47.1 \%)$ \\
Other & Not applicable & $0(0 \%)$ & $11(100 \%)$ \\
\hline
\end{tabular}

*This include amiodarone + beta-blockers and propafenone + beta-blockers; ${ }^{*}$ As the only therapy; IQR - interquartile range

Table 6. Results of primary pharmacological cardioversion (PCV).

\begin{tabular}{|c|c|c|c|c|c|c|}
\hline Details of PCV & $\begin{array}{c}\text { Total } \\
(\mathrm{n}=146)\end{array}$ & $\begin{array}{l}\text { Amiodarone or } \\
\text { amiodarone and } \\
\text { BB } \\
(n=76)\end{array}$ & $\begin{array}{l}\text { Propafenone } \\
\text { or propafenone } \\
\text { and BB } \\
n=36)\end{array}$ & $\begin{array}{l}\text { BB as the } \\
\text { only therapy } \\
(n=17)\end{array}$ & $\begin{array}{l}\text { Other } \\
(n=5)\end{array}$ & $\mathbf{P}$ \\
\hline $\begin{array}{l}\text { Time to primary } \\
\text { PCV }^{*}[\mathrm{~h}]\end{array}$ & $\begin{array}{c}2: 14 \\
(0: 30-17: 50)\end{array}$ & $\begin{array}{c}1: 40 \\
(0: 20-9: 50)\end{array}$ & $\begin{array}{c}1: 37 \\
(0: 36-5: 17)\end{array}$ & $\begin{array}{c}1: 40 \\
(1: 24-4: 36)\end{array}$ & $\begin{array}{c}24: 40 \\
(22: 20-27: 05)\end{array}$ & $<0.05$ \\
\hline $\begin{array}{l}\text { Successful } \\
\text { conversion }\end{array}$ & $110(75.3 \%)$ & $57(75.0 \%)$ & $25(69.4 \%)$ & $13(76.5 \%)$ & $4(80.0 \%)$ & 0.90 \\
\hline $\begin{array}{l}\text { Minutes to sinus } \\
\text { rhythm* }\end{array}$ & $\begin{array}{c}180.0 \\
(72.0-740.0)\end{array}$ & $\begin{array}{c}350.0 \\
(75.0-960.0)\end{array}$ & $\begin{array}{c}230.0 \\
(120.0-840.0)\end{array}$ & $\begin{array}{c}68.0 \\
(50.0-210.0)\end{array}$ & $\begin{array}{c}75.0 \\
(30.0-110.0)\end{array}$ & $<0.01$ \\
\hline $\begin{array}{l}\text { Duration of } \\
\text { hospital stay* }[\mathrm{h}]\end{array}$ & $\begin{array}{c}70: 38 \\
(17: 50-99: 03)\end{array}$ & $\begin{array}{c}84: 15 \\
(70: 14-145: 26)\end{array}$ & $\begin{array}{c}17: 48 \\
(7: 57-77: 51)\end{array}$ & $\begin{array}{c}7: 09 \\
(3: 08-41: 43)\end{array}$ & $\begin{array}{c}66: 35 \\
164: 00-69: 20\end{array}$ & $<0.0001$ \\
\hline
\end{tabular}

*Median (interquartile range); BB — beta-blockers 
dergo cardioversion of AF. General characteristics of the whole group and comparison with other registries are described in another publication [5]. We show safety and effectiveness of cardioversion in a "real life" registry, with consecutive patients included, with wide inclusion criteria and very limited exclusions.

The RHYTHM-AF registry shows statistics of the hospitalized patients with AF who underwent rhythm control strategy. Out of all 501 patients in the Polish RHYTHM-AF registry, 207 (41.3\%) did not undergo cardioversion, but this did not change rhythm control strategies. The most common reasons were planned cardioversion in the future and spontaneous SR restoration $(68.2 \%$ for both reasons). Contraindications to cardioversion were found only in $\sim 10 \%$ of all population; these included uncertain duration of current episodes of $\mathrm{AF}$, left atrial thrombus or spontaneous echo contrast. Left atrial thrombus was found in $16(3.2 \%)$ patients (in a large German cohort of over 3,000 patients with $\mathrm{AF}$ who underwent TEE, the frequency of thrombus in the left atrium was comparable [6]). In 8 patients, the rhythm control strategy was changed into rate control (cardioversion was not attempted because of size of the left atrium).

The mode of cardioversion (primary PCV and primary ECV) was largely dependent on the type of AF. Among patients who underwent ECV, paroxysmal $\mathrm{AF}$ was less frequent and persistent $\mathrm{AF}$ was more common, duration of the longest previous episode and current episode were completely different. This is consistent with current guidelines and previous studies $[1,3]$.

Effectiveness of ECV in our registry was comparable to that reported in the literature (78-97\%) [7-10]. Although some data suggest that in AF, $200 \mathrm{~J}$ energy should be started, especially in non-paroxysmal AF [11], we show that about $160 \mathrm{~J}$ energy may also be effective.

Pharmacological cardioversion was performed almost exclusively in patients with paroxysmal or first detected episodes of AF. According to current guidelines [1], almost all amiodarone patients were treated intravenously, oral formulation of propafenone was more common (71.8\%). In patients treated with propafenone and amiodarone, the addition of BB was considered a supplementary therapy, so patients treated with propafenone and propafenone with $\mathrm{BB}$ (or amiodarone and amiodarone in combination with $\mathrm{BB}$ ) were analyzed together. Separate analyses were performed for patients treated with $\mathrm{BB}$ alone. Demographic characteristics of patients treated with amiodarone, propafenone and $\mathrm{BB}$ were not statistically different, although hyperlipidemia and coronary disease occurred less frequently among patients treated with $\mathrm{BB}$, and none of these patients had a history of heart failure or myocardial infarction. Alternatively, although propafenone is contraindicated in patients with structural heart disease, $30 \%$ of patients treated with propafenone had a history of coronary disease, $25 \%$ a history of myocardial infarction and $25 \%$, a history of heart failure. The other problem is propafenone dosing - although separate dosing for intravenous and oral applications is not available, we can conclude that oral doses given to the patients are lower than recommended in the guidelines [1]. Amiodarone dosing seems to be adequate. Of special interest is the successful conversion rate in the small $(\mathrm{n}=17)$ group of patients treated with $\mathrm{BB}$ as the only therapy $-76.5 \%$. Previous (although very old) experiences with metoprolol were not encouraging with only $13 \%$ rate of conversion [12]. Time to reach SR in patients treated with $\mathrm{BB}$ was also very short (median was $68 \mathrm{~min}$ ), especially that almost half of the patients were treated orally. One might speculate that at least some of these episodes of AF would terminate spontaneously. Still, in relatively healthy populations with numerous previous episodes of AF that terminated spontaneously, adding a BB may be helpful in restoring SR.

The time to reach SR was the longest in patients treated with amiodarone and the shortest in patients treated with propafenone. This is consistent with other observations - in a meta-analysis, efficacy of cardioversion of $\mathrm{AF}$ with amiodarone was inferior to class Ic drugs for up to $8 \mathrm{~h}$ but no difference was observed at $24 \mathrm{~h}$ [13]. There were statistically significant differences in hospitalization time between patients treated with various pharmacological agents in PCV (with the longest duration being among patients in the amiodarone group), which may, in part, be due to the highest percentage of patients for whom AF was not a primary reason for admission into the amiodarone group, as well as the fact that amiodarone is known to have a far longer half-life, and takes a longer time to be effective [13].

We did not observe any clinical or echocardiographic parameters to vary significantly by the success of either primary PCV or ECV. Rate of complications was rather low, with single patients suffering serious complications including myocardial infarction, pulmonary embolism, or heart failure. A recent meta-analysis of $\mathrm{AF}$ cardioversion in emergency department shows comparable results [14]. 


\section{Limitations of the study}

This is one of a few studies showing fate of patients with AF who are hospitalized with an intention to be cardioverted. Thanks to wide inclusion criteria, patients from the cohort are likely to reflect real life patients. This was a purely observational study, and so by design, has certain limitations on the types of conclusions which can be drawn. Treatment groups were not randomized, but rather reflect real-world treatments, where they are given at the physicians' discretion, as were diagnostic tests and concomitant treatments, which were not made in a uniform fashion (for example echocardiography).

\section{Conclusions}

Less than $60 \%$ of the patients with AF admitted to the hospital with the intention to terminate arrhythmia eventually underwent an attempt of conversion to SR. Primary ECV was chosen in $51 \%$ of patients and was successful in $\sim 90 \%$ of the patients. PVC was successful in $\sim 75 \%$ of the patients. Amiodarone and propafenone were most commonly used with comparable efficacy. Rates of complications were low, with $\sim 2.8 \%$ of patients experiencing adverse events during hospitalization.

\section{Acknowledgements}

The study and manuscript were funded by Merck and Co., Inc. Dr Włodarczyk was a full time employee of MSD Poland at the time that this study was designed and performed.

Conflict of interest: Piotr Włodarczyk - Employee of MSD Poland

\section{References}

1. Camm J, Kirchhof P, Lip GYH et al. Wytyczne dotyczące postępowania u chorych z migotaniem przedsionków. Kardiol Pol, 2010; 68 (supl. VII): 487-566.
2. Stewart S, Hart CL, Hole DJ, McMurray JJ. A population-based study of the longterm risks associated with atrial fibrillation: 20-year follow-up of the Renfrew/Paisley study. Am J Med, 2002; 113: 359-364.

3. Van Gelder IC, Tuinenburg AE, Schoonderwoerd BS, Tieleman RG, Crijns HJ. Pharmacologic versus direct-current electrical cardioversion of atrial flutter and fibrillation. Am J Cardiol, 1999; 84: 147R-151R.

4. Crijns HJ, Bash LD, Chazelle F et al. RHYTHM-AF: Design of an international registry on cardioversion of atrial fibrillation and characteristics of participating centers. BMC Cardiovasc Disord, 2012; $12: 85$.

5. Dąbrowski R, Opolski G, Wlodarczyk P, Kiliszek M, Ponikowski P. Demographic and clinical characteristics of patients with atrial fibrillation and cardioversion as planned therapeutic options in the International Registry on Cardioversion of Atrial Fibrillation RHYTHM-AF Polish substudy. Kardiol Pol, 2014; 72: 700-706.

6. Wasmer K, Köbe J, Dechering D et al. CHADS(2) and CHA(2)DS (2)-VASc score of patients with atrial fibrillation or flutter and newly detected left atrial thrombus. Clin Res Cardiol, 2013; 102: 139-144.

7. Cristoni L, Tampieri A, Mucci F et al. Cardioversion of acute atrial fibrillation in the short observation unit: comparison of a protocol focused on electrical cardioversion with simple antiarrhythmic treatment. Emerg Med J, 2011; 28: 932-937.

8. Bellone A, Etteri M, Vettorello M et al. Cardioversion of acute atrial fibrillation in the emergency department: A prospective, randomized trial. Emerg Med J, 2012; 29: 188-191.

9. Vinson DR, Hoehn T, Graber DJ, Wiliams TM. Managing emergency department patients with recent-onset atrial fibrillation. J Emerg Med, 2012; 42: 139-148.

10. Dankner R, Shahar A, Novikov I, Agmon U, Ziv A, Hod H. Treatment of stable atrial fibrillation in the emergency department: A population-based comparison of electrical direct-current versus pharmacological cardioversion or conservative management. Cardiology. 2009; 112: 270-278.

11. Wozakowska-Kaplon B,Janion M, SielskiJ, RadomskaE, BakowskiD, Bartkowiak R. Efficacy of biphasic shock for transthoracic cardioversion of persistent atrial fibrillation: Can we predict energy requirements? Pacing Clin Electrophysiol, 2004; 27: 764-768.

12. Rehnqvist $\mathrm{N}$. Clinical experience with intravenous metoprolol in supraventricular tachyarrhythmias. A multicentre study. Ann Clin Res, 1981; 13 (suppl. 30): 68-72.

13. Chevalier P, Durand-Dubief A, Burri H, Cucherat M, Kirkorian G, Touboul P. Amiodarone versus placebo and class Ic drugs for cardioversion of recent-onset atrial fibrillation: A meta-analysis. J Am Coll Cardiol, 2003; 41: 255-262.

14. Coll-Vinent B, Fuenzalida C, García A, Martín A, Miró Ò. Management of acute atrial fibrillation in the emergency department: A systematic review of recent studies. Eur J Emerg Med, 2013; 20: 151-159. 